\title{
Prognostic value of plasma N-terminal pro-B-type natriuretic peptide concentration in patients with normal and impaired left ventricular systolic function undergoing surgery for abdominal aortic aneurysm
}

Marek Waliszek ${ }^{1}$, Agnieszka Waliszek-Iwanicka², Tomasz Grycewicz³, Piotr Jurowski ${ }^{4}$, Maciej Banach5, Jacek Rysz ${ }^{6}$, Aleksander Goch?

${ }^{1}$ Cardiac Diagnostics Unit, M. Pirogow Provincial Specialist Hospital, Lodz, Poland 2Provincial Centre of Diabetology and Metabolic Diseases, M. Pirogow Provincial Specialist Hospital, Lodz, Poland

${ }^{3}$ Department of Interventional Cardiology, Cardiodiabetology and Cardiac Rehabilitation, Medical University, Lodz, Poland

${ }^{4}$ Department of Ophthalmology and Visual Rehabilitation, Medical University of Lodz, Poland

${ }^{5}$ Department of Hypertension, Medical University of Lodz, Poland

${ }^{6}$ Department of Nephrology, Hypertension and Family Medicine, Medical University of Lodz, Poland

7Department of Cardiology and Cardiosurgery, Clinical Military Hospital, Bydgoszcz, Poland

Submitted: 24 October 2010

Accepted: 28 December 2010

Arch Med Sci 2011; 7, 4: 642-647

DOI: 10.5114/aoms.2011.24134

Copyright (c) 2011 Termedia \& Banach

\section{Abstract}

Introduction: Implantation of an aortic-bifemoral prosthesis is characterised by a high (> 5\%) rate of perioperative cardiovascular events. The main aim of the study is to demonstrate the usefulness of the determination of NT-proBNP concentration as a method of risk stratification of left ventricular dysfunction in patients subjected to surgery for aortic-bifemoral prosthesis implantation. Material and methods: Forty consecutive patients were examined and subjected to aortic-bifemoral prosthesis implantation. The examined patients were divided into two groups: 1) with normal left ventricular systolic function and $E F \geq 58 \%$ (group I), 2) with left ventricular systolic dysfunction and EF $<58 \%$ (group II). Results: In group I the median EF before surgery was $69.5 \%$ and the concentration of NT-proBNP $141.5 \mathrm{pg} / \mathrm{ml}$. On day 7 after surgery respective values were EF $65.5 \%$, NT-proBNP $498.55 \mathrm{pg} / \mathrm{ml}$. In group II the median EF before surgery was $54 \%$, and NT-proBNP concentration $303.9 \mathrm{pg} / \mathrm{ml}$.

Conclusions: The concentration of plasma NT-proBNP before surgery well correlated with left ventricular ejection fraction. The values of NT-proBNP > 303.9 $\mathrm{pg} / \mathrm{ml}$ strongly correlated with increased risk of left ventricular systolic dysfunction after surgery and they seem to have high prognostic value for the occurrence of cardiovascular events in this group of patients. The determination of NT-proBNP level on day 7 after surgery strongly correlated with the decrease of left ventricular ejection fraction in patients after the prosthesis implantation. It is a valuable diagnostic and prognostic factor of circulatory system efficiency before making a decision to discontinue hospitalization.

Key words: NT-proBNP, abdominal aortic aneurysm, Leriche syndrome, clamping syndrome, heart failure.

\author{
Corresponding author: \\ Marek Waliszek Md, PhD \\ Cardiac Diagnostics Unit \\ M. Pirogow Provincial \\ Specialist Hospital \\ 33/10 Maratonska \\ 94-102 Lodz, Poland \\ Phone: +48 692429080 \\ E-mail: \\ markkris@poczta.onet.pl
}




\section{Introduction}

Major non-cardiac surgical procedures are associated with significant postoperative morbidity and mortality. The majority of deaths in this setting correlate with cardiac complications such as myocardial infarction. Major surgery is also associated with increased prevalence of stroke, non-fatal myocardial ischaemia and malignant arrhythmia. So far, a few systems have been described for the estimation of perioperative risk in this group of patients.

Implantation of an aortic-bifemoral prosthesis is characterised by a high ( $>5 \%$ ) rate of perioperative cardiovascular events. The risk stratification of complications in non-cardiac surgical procedures is difficult in this population of patients; it is difficult to estimate cardiovascular system efficiency due to the basic disease preventing patients from making even a slight effort. In patients with asymptomatic and symptomatic heart failure N-terminal pro-B-type natriuretic peptide (NT-proBNP) concentration is a strong predictor of cardiovascular events or death $[1,2]$.

The main aim of the study is to demonstrate the usefulness of the determination of plasma NT-proBNP concentration as a method of risk stratification of left ventricular dysfunction in patients with Leriche's syndrome and abdominal aortic aneurysm subjected to surgery for aortic-bifemoral prosthesis implantation.

\section{Material and methods}

\section{Study group}

Forty consecutive patients were examined and subjected to aortic-bifemoral prosthesis implantation in the Vascular Surgery Unit of M. Pirogow Provincial Specialist Hospital in Lodz within the period from September 2007 to April 2008. All the study participants had signed the consent form before they were included in the study, which was approved by the local Ethics Committee of the Medical University of Lodz.

The examined patients were divided into two groups: 1) with normal left ventricular systolic function and ejection fraction (EF) $\geq 58 \%$ (group I), 2) with left ventricular systolic dysfunction and $E F$ $<58 \%$ (group II).

Each group included 20 examined patients in the same age range. The patients from both groups were selected for the examination after prior qualification for surgery by vascular surgery specialists from M. Pirogow Hospital in Lodz. All the patients qualified for surgical procedure were subjected to the following examinations:

- ultrasonographic (USG) of abdominal aorta and lower limb vessels,
- abdominal computed tomography (CT) or abdominal aorta angiography,

- thoracic X-ray,

- arterial blood pressure measurement by Korotkov's method and pulse evaluation,

- electrocardiogram (ECG),

- echocardiography with EF evaluation using modified Simpson's technique according to the guidelines of the American Society of Echocardiography before surgery and on day 7 after the procedure,

- laboratory blood tests: blood cell count, electrolytes, glucose, urea, creatinine, total cholesterol, $\mathrm{LDL}, \mathrm{HDL}$, triglycerides,

- determination of NT-proBNP level before surgery and on day 7 after the procedure using the immunochemical electroluminescence method worked out by Roche Diagnostics, on an Elecsys 2010 analyser.

\section{Characteristics of the examined group}

Clinical assessment of the risk of cardiac events was carried out in accordance with the cardiac risk index according to Lee et al. [3]. A preoperative cardiac risk score was calculated by assigning 1 point to each of the following cardiac risk factors: high-risk type of surgery (> 5\%), ischaemic heart disease or previous myocardial infarction, history of heart failure, history of cerebrovascular disease or previous stroke, insulin therapy for diabetes mellitus, renal dysfunction (defined as preoperative serum creatinine level $>2.0 \mathrm{mg} / \mathrm{dl}[177 \mu \mathrm{mol} / \mathrm{l}])$.

Detailed characteristics of the examined groups are presented in Table I. Implantation of an aorticbifemoral prosthesis was performed in 24 patients with abdominal aortic aneurysm and in 16 patients with Leriche's syndrome.

All surgical procedures were performed under general anaesthesia. In the perioperative period standard medical care was supplied. The duration of the surgery was registered as well as of abdominal aortic clamping and blood loss in the course of the surgery (Table II).

\section{Statistical analysis}

Nonparametric statistics was used for the comparison of two variables based on the Wilcoxon rank sum test. The procedure assumes that the considered variables were measured on a scale enabling one to rank observations within each variable (ordinal scale) and to rank the differences between variables. The EF, NT-proBNP, HR, haemoglobin and haematocrit values were compared before surgery and on day 7 after the procedure. The duration of the surgery and aortic clamping as well as blood loss during the procedure were also analysed. 


\section{Results}

The study population consisted of 20 patients with normal left ventricular systolic function and $E F \geq 58 \%$ (group I) and 20 patients with left ventricular systolic dysfunction (group II). The mean age in group I was $58.1 \pm 17.7$ years (70\% men), in group II $55.3 \pm 25.6$ years ( $85 \%$ men). In the group with normal systolic function 5 patients (25\%) had

Table I. Characteristics of the examined groups

\begin{tabular}{|c|c|c|c|}
\hline $\begin{array}{l}\text { Characteristics } \\
\text { of the examined } \\
\text { groups }\end{array}$ & $\begin{array}{l}\text { Group I } \\
\text { EF > 58\% } \\
n=20\end{array}$ & $\begin{array}{c}\text { Group II } \\
\text { EF }<58 \% \\
n=20\end{array}$ & Value of $p$ \\
\hline Age [years] & $58.1 \pm 17.7$ & $55.3 \pm 25.6$ & NS \\
\hline Men [\%] & 70 & 85 & NS \\
\hline $\mathrm{BMI}\left[\mathrm{kg} / \mathrm{m}^{2}\right]$ & $25.1 \pm 4.4$ & $24.9 \pm 4$ & NS \\
\hline BSA & $1.9 \pm 0.2$ & $1.9 \pm 0.2$ & NS \\
\hline IHD [\%] & 25 & 60 & $<0.05$ \\
\hline $\begin{array}{l}\text { Previous myocardial } \\
\text { infarction [\%] }\end{array}$ & 5 & 35 & $<0.05$ \\
\hline Heart failure [\%] & 20 & 40 & NS \\
\hline $\begin{array}{l}\text { Previous CNS } \\
\text { ischaemia [\%] }\end{array}$ & 0 & 0 & NS \\
\hline Previous CABG [\%] & 0 & 5 & NS \\
\hline Renal failure [\%] & 10 & 5 & NS \\
\hline Hypertension [\%] & 75 & 70 & NS \\
\hline Diabetes [\%] & 0 & 20 & $<0.05$ \\
\hline $\begin{array}{l}\text { Hypercholestero- } \\
\text { laemia [\%] }\end{array}$ & 45 & 50 & NS \\
\hline Cigarette smoking [\%] & 65 & 60 & NS \\
\hline Abnormal ECG [\%] & 25 & 60 & $<0.05$ \\
\hline $\begin{array}{l}\text { Pathological Q } \\
\text { waves [\%] }\end{array}$ & 5 & 25 & $<0.05$ \\
\hline $\begin{array}{l}\text { Wall motion abnor- } \\
\text { malities at rest [\%] }\end{array}$ & 5 & 45 & $<0.05$ \\
\hline LV hypertrophy [\%] & 40 & 40 & NS \\
\hline $\begin{array}{l}\text { Abdominal aortic } \\
\text { aneurysm [\%] }\end{array}$ & 65 & 55 & NS \\
\hline Leriche's syndrome [\%] & 35 & 45 & NS \\
\hline ASA [\%] & 20 & 75 & $<0.05$ \\
\hline ACEI [\%] & 60 & 60 & NS \\
\hline Sartans [\%] & 10 & 5 & NS \\
\hline$\beta$-Blockers [\%] & 40 & 45 & NS \\
\hline Calcium antagonists [\%] & 15 & 10 & NS \\
\hline Digoxin [\%] & 0 & 0 & NS \\
\hline Diuretics [\%] & 20 & 30 & NS \\
\hline Nitrates [\%] & 0 & 25 & $<0.05$ \\
\hline Statins [\%] & 30 & 55 & $<0.05$ \\
\hline
\end{tabular}

$n$-number of patients, $p$-difference significant, NS - difference statistically insignificant confirmed ischaemic heart disease (IHD), and 1 of them had a history of myocardial infarction. In group II, 12 patients had IHD (60\%), 7 myocardial infarction (35\%), and 1 previous surgical myocardial revascularisation.

The number of examined patients in both groups according to cardiac risk index according to Lee [3] is presented in Table III.

In group I the median left ventricular EF before surgery was $69.5 \%\left(1^{\text {st }}\right.$ and $3^{\text {rd }}$ quartile respectively $67 \%$ and $73.3 \%$ ), and the concentration of NT-proBNP $141.5 \mathrm{pg} / \mathrm{ml}\left(1^{\text {st }}\right.$ and $3^{\text {rd }}$ quartile respectively $101.64 \mathrm{pg} / \mathrm{ml}$ and $210.78 \mathrm{pg} / \mathrm{ml}$ ). On day 7 after surgery respective values were EF $65.5 \%$ $\left(1^{\text {st }}\right.$ and $3^{\text {rd }}$ quartile respectively $63.75 \%$ and $73.32 \%$ ), NT-proBNP $498.55 \mathrm{pg} / \mathrm{ml}$ ( $1^{\text {st }}$ and $3^{\text {rd }}$ quartile respectively $232.33 \mathrm{pg} / \mathrm{ml}$ and $744.5 \mathrm{pg} /$ $\mathrm{ml})$. No statistical significance was observed for the decrease of ejection fraction $(p=0.432622)$. However, a statistically significant increase of the value of serum NT-proBNP concentration was detected on day 7 after implantation of the aorticbifemoral prosthesis ( $p=0.000219)$.

In group II the median left ventricular ejection fraction (EF) before surgery was $54 \%\left(1^{\text {st }}\right.$ and $3^{\text {rd }}$ quartile respectively $52.75 \%$ and $55.78 \%$ ), and NT-proBNP concentration $303.9 \mathrm{pg} / \mathrm{ml}\left(1^{\text {st }}\right.$ and $3^{\text {rd }}$ quartile respectively $213.95 \mathrm{pg} / \mathrm{ml}$ and 543.13 $\mathrm{pg} / \mathrm{ml})$. On day 7 after surgery a statistically significant decrease of left ventricular ejection fraction was observed to $50.5 \%\left(1^{\text {st }}\right.$ and $3^{\text {rd }}$ quartile respectively $49 \%$ and $52.25 \%$ ), whereas the median NT-proBNP increased statistically significantly to $1522.8 \mathrm{pg} / \mathrm{ml}$ ( $1^{\text {st }}$ and $3^{\text {rd }}$ quartile respectively $834.98 \mathrm{pg} / \mathrm{ml}$ and $3431 \mathrm{pg} / \mathrm{ml}$ ). The examined groups did not differ statistically significantly as regards the duration of the surgery, the duration of aortic clamping or blood loss during the procedure.

Comparing both groups on day 7 after surgery, a significant increase of NT-proBNP concentration was observed (median $1522.8 \mathrm{pg} / \mathrm{ml}$ ) in group I of patients with initially decreased EF $<58 \%$ in relation to the examined patients in group II with initially increased EF > 58\% (median $498.55 \mathrm{pg} / \mathrm{ml}$ ), and a significant decrease of left ventricular ejection fraction in group II patients with initially decreased $\mathrm{EF}<58 \%$ (Figures 1 and 2).

In group I on day 7 after implantation of the aortic-bifemoral prosthesis the increased plasma NT-proBNP level was accompanied by a statistically insignificant increase of mean heart rate (HR) by $2.3 \%$ ( $p=0.433054)$. In group II on day $7 \mathrm{HR}$ increased statistically significantly by $13.6 \%$ $(p=0.000780)$.

A comparable decrease of HCT and HGB value was observed in both groups on day 7 after implantation of the aortic-bifemoral prosthesis in relation to the initial values (Table IV). 
Prognostic value of plasma N-terminal pro-B-type natriuretic peptide concentration in patients with normal and impaired left ventricular systolic function undergoing surgery for abdominal aortic aneurysm

Table II. Mean values \pm standard deviations of the duration of surgery, abdominal aortic clamping (in minutes) and blood loss (in $\mathrm{ml}$ ) in group I and II

\begin{tabular}{|lccl|}
\hline Parameters & $\begin{array}{c}\text { Group I } \\
\mathrm{EF}>58 \% \\
n=20\end{array}$ & $\begin{array}{c}\text { Group II } \\
\mathrm{EF}<58 \% \\
n=20\end{array}$ & Value of $p$ \\
\hline $\begin{array}{l}\text { Duration of surgery } \\
132.3 \pm 31.9\end{array}$ & $135.0 \pm 32.4$ & NS \\
\hline $\begin{array}{l}\text { Duration of aortic } \\
\text { clamping }\end{array}$ & $38.5 \pm 14.6$ & $35.2 \pm 9.5$ & NS \\
\hline Blood loss & $900.5 \pm 521.4$ & $946 \pm 430.7$ & NS \\
\hline
\end{tabular}

$n$ - number of patients, $p$ - difference significant, NS - difference statistically insignificant

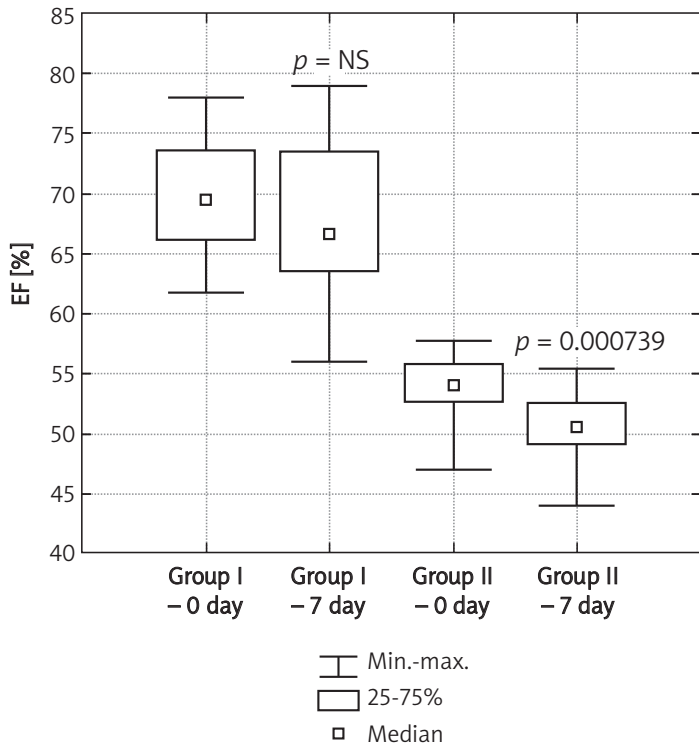

Figure 1. Comparison of the value of left ventricular ejection fraction in groups I and II before surgery (day 0 ) and on day 7 after implantation of aorticbifemoral prosthesis

\section{Discussion}

The level of NT-proBNP is useful information in patients with suspected heart failure and a valuable prognostic marker in patients with heart failure, acute coronary syndromes, valvular heart disease or other circulatory system pathologies. Increasing numbers of studies confirm that elevated BNP and NT-proBNP levels predict many causes of mortality and cardiovascular events including heart failure, myocardial infarction, shock, atrial fibrillation and sudden death in stable patients with known or unknown circulatory system disease, and they provide information about cardiovascular risk regardless of the risk factors used so far $[4,5]$. Also in low risk patients with stable ischaemic heart disease and preserved ventricular function, BNP and NT-proBNP are highly sensitive and specific prognostic markers in comparison to standard risk
Table III. Number of examined patients in particular groups acc. to cardiac risk index acc. to Lee

\begin{tabular}{|lccc|}
\hline $\begin{array}{l}\text { Cardiac risk index } \\
\text { acc. to Lee }\end{array}$ & $\begin{array}{c}\text { Group I } \\
\mathrm{EF}>58 \% \\
n=20\end{array}$ & $\begin{array}{c}\text { Group II } \\
\mathrm{EF}<58 \% \\
n=20\end{array}$ & Value of $p$ \\
\hline 1 & 12 & 5 & $<0.05$ \\
\hline 2 & 6 & 6 & NS \\
\hline 3 & 2 & 7 & $<0.05$ \\
\hline 4 & 0 & 2 & NS \\
\hline
\end{tabular}

$n$ - number of patients, $p$-difference significant, NS - difference statistically insignificant

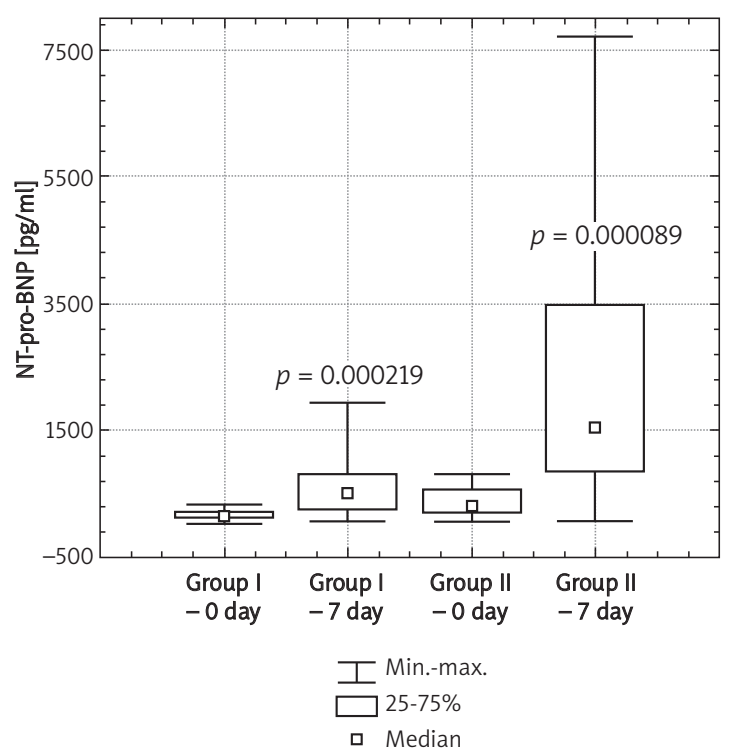

Figure 2. Comparison of the value of plasma NT-proBNP concentration in groups I and II before surgery (day 0 ) and on day 7 after implantation of aortic-bifemoral prosthesis

factors [6]. High sensitivity and diagnostic specificity of NT-proBNP was demonstrated in oligosymptomatic left ventricular dysfunction defined as left ventricular ejection fraction $<58 \%[6,7]$. One of the most significant diagnostic applications of natriu-

Table IV. Comparison of HGB and HCT values in Group I and II before (0) and on day 7 after surgery

\begin{tabular}{|c|c|c|c|}
\hline \multirow{4}{*}{$\begin{array}{l}\text { Group I } \\
\text { EF > 58\% } \\
n=20\end{array}$} & HGB - day 0 & $13.8 \pm 1.8$ & \multirow[t]{2}{*}{$p=0.001697$} \\
\hline & HGB - day 7 & $11.9 \pm 1.5$ & \\
\hline & HCT - day 0 & $40.3 \pm 4.9$ & \multirow[t]{2}{*}{$p=0.001475$} \\
\hline & HCT - day 7 & $34.4 \pm 4.2$ & \\
\hline \multirow{4}{*}{$\begin{array}{l}\text { Group II } \\
\text { EF }<58 \% \\
n=20\end{array}$} & HGB - day 0 & $13.7 \pm 1.6$ & \multirow[t]{2}{*}{$p=0.002979$} \\
\hline & HGB - day 7 & $11.8 \pm 1.8$ & \\
\hline & HCT - day 0 & $39.9 \pm 4.2$ & \multirow[t]{2}{*}{$p=0.009637$} \\
\hline & HCT - day 7 & $33.7 \pm 5.2$ & \\
\hline
\end{tabular}


retic peptides determination is their high negative predictive value, reaching $99 \%$, excluding heart failure [8].

In the group of patients subjected to aorticbifemoral prosthesis implantation it is very important to establish the risk of cardiovascular events, particularly in older patients who probably have circulatory system disease and whose reaction to transfusion and fluid therapy may decompensate their circulatory system. Furthermore, their cardiovascular system is exposed to the increase of afterload during aortic clamping as well as to early or late post-perfusion syndrome. There are only single reports concerning studies on the relation of the level of plasma natriuretic peptides as a prognostic factor of morbidity and mortality of patients subjected to major non-cardiac surgery, particularly to the implantation of an aorticbifemoral prosthesis.

Feringa et al. evaluated 170 patients: 67 (39\%) were subjected to abdominal aortic repair, and 103 (61\%) to lower extremity revascularization. During a follow-up of 30 days the patients were observed as regards cardiac events. The aim of the study was to assess the value of NT-proBNP for predicting postoperative cardiac events in patients undergoing major non-cardiac surgery, in addition to clinical data and dobutamine stress echocardiographic results. The median NT-proBNP level was higher in the group of patients with postoperative cardiac events (939 pg/ml, interquartile range from 634 to 2469) compared with patients with no cardiac events (101 pg/ml, interquartile range from 40 to 304) $(p<0.0001)$. The level of NT-proBNP $\geq 533 \mathrm{pg} / \mathrm{ml}$ was identified as the optimal predictor of postoperative cardiac events in these patients [9]. In a consecutive prospective study in 182 vascular surgery patients, the association was evaluated between NT-proBNP concentration, myocardial ischaemia, troponin T level and HRV. Elevated level of NT-proBNP $\geq 270 \mathrm{ng} / \mathrm{l}$ was associated with higher perioperative risk of myocardial ischaemia and troponin T release. No correlation was found between preoperative HRV and NT-proBNP levels [10].

In a study on two groups -41 patients with very high risk of cardiovascular events subjected to high risk surgical procedures (amputation, aortic surgery, peripheral bypass) who participated in the North Glasgow MONICA study and 149 patients from a low cardiac risk group undergoing major noncardiosurgical procedures (vascular procedures, laparotomies, thoracotomies) - the usefulness of preoperative determination of the BNP level for predicting postoperative cardiac events was analysed. Preoperative level of BNP > 108.5 pg/ml was demonstrated to predict in both groups postoperative cardiac events in patients subjected to major non-cardiac procedures with $87 \%$ sensitivity and specificity regardless of other risk factors 11].

In another study investigating the usefulness of the determination of BNP level in risk stratification of cardiac events in patients subjected to major non-cardiac surgery, it was demonstrated that the level of BNP > $40 \mathrm{pg} / \mathrm{ml}$ with $75 \%$ sensitivity and $70 \%$ specificity was associated with higher risk of perioperative myocardial infarction and death. The patients who in the postoperative period had ECG abnormalities and elevated troponin I level demonstrated higher preoperative plasma BNP levels [12].

Yeh et al. demonstrated that the level of NT-proBNP > $450 \mathrm{pg} / \mathrm{ml}$ predicted postoperative cardiac events in 190 patients undergoing noncardiac surgery. Fifteen of 190 patients had cardiac complications: 4 - acute coronary syndrome, 13 heart failure. The NT-pro-BNP level was significantly higher in patients with cardiac complications; a level > $450 \mathrm{ng} / \mathrm{ml}$ was predictive of cardiac complications with a sensitivity of $100 \%$ and specificity of $82.9 \%$ [13].

However, in another study based on 1590 patients it was demonstrated that preoperative level of BNP > $189 \mathrm{pg} / \mathrm{ml}$ was the only independent factor identifying patients at highest risk of postoperative cardiovascular events in comparison to Goldman's multifactorial index of cardiac risk [14] and to left ventricular ejection fraction [15]. Cardiac events occurred in $6 \%$ of patients: 21 cardiac deaths, 20 non-fatal myocardial infarctions, 41 episodes of pulmonary oedema and 14 patients with ventricular tachycardia. All these patients had a preoperative level of BNP > $189 \mathrm{pg} / \mathrm{ml}$. It should be mentioned that in this study 15 patients with serious postoperative cardiac events had a level of BNP $<189 \mathrm{pg} / \mathrm{ml}$ and 233 patients without any postoperative cardiac events had an elevated BNP level greater than $189 \mathrm{pg} / \mathrm{ml}$. In this study there were no patients with postoperative cardiac events and an initial level of BNP $<100 \mathrm{pg} / \mathrm{ml}$, and no patients with a history of cardiac events and an initial level of BNP $<100 \mathrm{pg} / \mathrm{ml}$ which does not exclude a history of myocardial infarction or asymptomatic left ventricular dysfunction.

In this study values of NT-proBNP > $303.9 \mathrm{pg} / \mathrm{ml}$ strongly correlated with increased risk of left ventricular systolic dysfunction after implantation of the aortic-bifemoral prosthesis and they seem to have high prognostic value for the occurrence of postoperative cardiovascular events in this group of patients. They distinguish a group of patients requiring special preoperative pharmaceutical preparation, particularly normalization of waterelectrolyte balance and preoperative $\beta$-blockade [16]. The statement seems to be right that the determination of plasma natriuretic level in 
perioperative risk stratification of aortic-bifemoral prosthesis implantation is a marker of cardiovascular events independent of left ventricular echocardiography and it is valuable information about perioperative circulatory system efficiency at low cost of the diagnostic test [17].

In conclusion, the concentration of plasma NT-proBNP before aortic-bifemoral prosthesis implantation correlated well with left ventricular ejection fraction. The values of NT-proBNP > 303.9 $\mathrm{pg} / \mathrm{ml}$ strongly correlated with increased risk of left ventricular systolic dysfunction after aorticbifemoral prosthesis implantation and they seem to have high prognostic value for the occurrence of cardiovascular events in this group of patients. The determination of NT-proBNP level on day 7 after aortic-bifemoral prosthesis implantation strongly correlated with the decrease of left ventricular ejection fraction in patients after prosthesis implantation. It is a valuable diagnostic and prognostic factor of circulatory system efficiency before making a decision to discontinue hospitalization.

\section{References}

1. Doust JA, Pietrzak E, Dobson A, Glasziou P. How well does B-type natriuretic peptide predict death and cardiac events in patients with heart failure: systematic review. BMJ 2005; 330: 625.

2. Masson S, Latini R, Anand IS, et al. Cohn on behalf of the Val-HeFT Investigators. Direct comparison of B-type natriuretic peptide (BNP) and amino-terminal proBNP in a large population of patients with chronic and symptomatic heart failure: the valsartan heart failure (ValHeFT) data. Clin Chem 2006; 52: 1528-38.

3. Lee TH, Marcantonio ER, Mangione CM, et al. Derivation and prospective validation of a simple index for prediction of cardiac risk of major noncardiac surgery. Circulation 1999; 100: 1043-9.

4. Campbell DJ. Can measurement of B-type natriuretic peptide levels improve cardiovascular disease prevention? Clin Exp Pharmacol Physiol 2008; 35: 442-6.

5. Trojnarska O, Bręborowicz P, Gwizdała A, et al. B-type natriuretic peptide level in adult patients after successful repair of coarctation of the aorta. Arch Med Sci 2008; 4: 274-7.

6. Omland T, Sabatine MS, Jablonski KA, et al.; PEACE Investigators. Prognostic value of B-type natriuretic peptides in patients with stable coronary artery disease: the PEACE trial. J Am Coll Cardiol 2007; 50: 215-6.

7. Groenning BA, Nilsson JC, Sondergaard L, et al. Detection of left ventricular enlargement and impaired systolic function with plasma $\mathrm{N}$-terminal pro-brain natriuretic peptide concentrations. Am Heart J 2002; 143: 923-9.

8. McDonagh TA, Holmer S, Raymond I, Luchner A, Hildebrant P, Dargie HJ. NT-proBNP and the diagnosis of heart failure: a pooled analysis of three European epidemiological studies. Eur J Heart Fail 2004; 6: 269-73.

9. Feringa HH, Bax JJ, Elhendy A, et al. Association of plasma $\mathrm{N}$-terminal pro-B-type natriuretic peptide with postoperative cardiac events in patients undergoing surgery for abdominal aortic aneurysm or leg bypass. Am J Cardiol 2006; 98: 111-5.
10. Feringa HH, Vidakovic R, Karagiannis SE, et al. Baseline natriuretic peptide levels in relation to myocardial ischemia, troponin $\mathrm{T}$ release and heart rate variability in patients undergoing major vascular surgery. Coron Artery Dis 2007; 18: 645-51.

11. Gibson SC, Payne CJ, Byrne DS, Berry C, Dargie HJ, Kingsmore DB. B-type natriuretic peptide predicts cardiac morbidity and mortality after major surgery. Br I Surg 2007; 94: 903-9.

12. Cuthbertson BH, Amiri AR, Croal BL, et al. Utility of B-type natriuretic peptide in predicting perioperative cardiac events in patients undergoing major non-cardiac surgery. Br J Anaesth 2007; 99: 151-4.

13. Yeh HM, Lau HP, Lin JM, Sun WZ, Wang MJ, Lai LP. Preoperative plasma $\mathrm{N}$-terminal pro-brain natriuretic peptide as a marker of cardiac risk in patients undergoing elective non-cardiac surgery. Br J Surg 2005; 92: 1041-5.

14. Goldman L, Caldera DL, Nussbaum SR, et al. Multifactorial index of cardiac risk in noncardiac surgical procedures. N Engl J Med 1977; 297: 845-50.

15. Dernellis J, Panaretou M. Assessment of cardiac risk before non-cardiac surgery: brain natriuretic peptide in 1590 patients. Heart 2006; 92: 1645-50.

16. Kern JW, Shoemaker WC. Meta-analysis of hemodynamic optimization in high-risk patients. Crit Care Med 2002; 30: 1686-92.

17. Gackowski A, Isnard R, Golmard JL, et al. Comparison of echocardiography and plasma B-type natriuretic peptide for monitoring the response to treatment in acute heart failure. Eur Heart J 2004; 25: 1788-96. 